\begin{tabular}{|l|c|c|c|c|}
\hline $\begin{array}{l}\text { Cuadernos de Investigación Geográfica } \\
\text { Geographical Research Letters }\end{array}$ & 2019 & N $^{\circ} 45(2)$ & pp. 729-750 & eISSN 1697-9540 \\
\hline
\end{tabular}

DOI: http://doi.org/10.18172/cig.3721

(C) Universidad de La Rioja

\title{
DINAMISMO, COMPLEJIDAD Y ESPECIFICIDAD DE LOS LITORALES ESTUARINOS: ANÁLISIS DE LA DINÁMICA LITORAL EN PUNTA ATALAYA, BUENOS AIRES, ARGENTINA
}

\author{
G. D'AMICO ${ }^{1,2,3 *}$, E. FUCKS ${ }^{1}$, C. CARUT ${ }^{2}$ \\ ${ }^{1}$ Centro de Estudios de la Dinámica Exógena, Universidad Nacional de La Plata, \\ C1925 La Plata, Buenos Aires, Argentina. \\ ${ }^{2}$ Instituto de Investigaciones en Humanidades y Ciencias Sociales, Universidad Nacional de La Plata- \\ Consejo Nacional de Investigaciones Científicas y Técnicas, Argentina. \\ ${ }^{3}$ Consejo Nacional de Investigaciones Científicas y Técnicas, Argentina.
}

RESUMEN. Los litorales son espacios complejos y dinámicos, producto de la interacción entre las dinámicas naturales y las valoraciones sociales a lo largo del tiempo. Esta interacción desencadena procesos variados que confieren especificidad a sus costas. En los litorales estuarinos se forman ambientes intermareales denominados marismas, intensamente modificadas en las grandes metrópolis urbanas. La dinámica de estos ambientes ha sido extensamente estudiada en el hemisferio norte, encontrándose escasas investigaciones en el hemisferio sur. En el presente trabajo se realiza un estudio multitemporal de una marisma de formación reciente en la costa de Punta Atalaya (partido de Magdalena, Buenos Aires, Argentina), situada en el sector intermedio de la costa argentina del estuario del Río de la Plata, utilizando la línea de costa como indicador del límite exterior de este ambiente. Se partió de su identificación en fotografías aéreas e imágenes de satélites de alta resolución en el periodo 1929-2016. Mediante la utilización de un software especializado en el análisis multitemporal de cambios, inspecciones en el campo y revisión de bibliografía general y específica, se realizó una aproximación explicativa de la dinámica litoral de esta franja territorial. Se determinó que la costa de Punta Atalaya presenta una tendencia progradante en el último siglo, aunque cambios en la microescala temporal y espacial son detectados a lo largo de todo el periodo, respondiendo a dinámicas acrecionales y erosivas que derivan de la interacción de procesos biológicos, sedimentarios, meteorológicos y sociales. Cada proceso puede desencadenar múltiples respuestas y tener impactos diferenciales en tiempo y espacio. En este sentido, se cuestionan las nociones de equilibrio utilizadas en las clásicas investigaciones acerca de los balances sedimentarios costeros. El sector correspondiente al área de estudio no posee categoría de área protegida, por lo que su valoración ambiental en este sentido debe contemplar la dinámica del mismo. 


\title{
Dynamism, complexity and specificity of the estuarine littorals: analysis of the littoral in Punta Atalaya, Buenos Aires, Argentina
}

\begin{abstract}
Littorals are complex and dynamic spaces, as a result of the interaction between natural dynamics and social assessments over time. This interaction triggers multiple processes, which lend specificity to their coasts. Intertidal environments called marshes are developed in estuarine littorals, which have been intensely modified in large urban metropolises. These environments dynamics have been extensively studied in the northern hemisphere, but scarce research has been performed in the southern hemisphere. In the present work a multitemporal study of a recent developed marsh is done in the coast of Punta Atalaya (district of Magdalena, Buenos Aires, Argentina), located along the intermediate sector of the Argentine coast of the Río de la Plata estuary, using the coastline as an indicator, considering it as the outer limit of this environment. The study was based on its identification in aerial photographs and high-resolution satellite images during the 1929-2016 period. Using specialized software for the multi-temporal change analysis, field work and general and specific bibliography review, an explanatory approximation of the littoral dynamics of this territory was performed. It was determined that the coast of Punta Atalaya presents an accretional tendency during the last century, although changes in the temporal and spatial micro scale are detected throughout the period, responding to accretional and erosive dynamics that derive from the interaction of biological, sedimentary, meteorological and social processes. Each process can trigger multiple responses and have differential impacts in time and space. In this sense, the concepts of balance used in the classic coastal sedimentary balance investigations are questioned.
\end{abstract}

The study area does not have a protected area category, so its environmental assessment in this sense must consider dynamical processes.

Palabras clave: litoral, estuario, marisma, línea de costa, Argentina.

Key words: littorals, estuary, marsh, coastline, Argentina.

Recibido: 23 de agosto de 2018 Aceptado: 21 de noviembre de 2018

*Correspondencia: G. D’Amico, Centro de Estudios de la Dinámica Exógena, Universidad Nacional de La Plata, C1925 La Plata, Buenos Aires, Argentina. E-mail: gdamico@fahce.unlp.edu.ar

\section{Introducción}

Los espacios litorales, al ser una interfaz entre los medios terrestre, acuático y atmosférico, constituyen ambientes en constante cambio, producto de la interrelación entre sus dinámicas y componentes. Procesos hidrológicos, climáticos, bioquímicos, 
geomorfológicos (Perillo et al., 2007) y la impronta de la acción antrópica, interactúan modelando estos espacios. Dichos procesos se desarrollan en la zona de interposición efectiva, una franja de interacción entre los ámbitos terrestres y acuáticos donde se localizan las formas litorales, como playas, marismas, dunas, entre otras (Carut, 2014). Dentro de los ambientes litorales, los estuarios han sido históricamente valorados por su condición de abrigo desde los inicios de la navegación hasta nuestros días, ya que constituyen áreas propicias para la ubicación de puertos. Esta impronta se manifiesta en aquellos que albergan a grandes metrópolis, como las de Londres, Lisboa, Roma, Amsterdam, Nueva York y Buenos Aires (Carut, 2014), esta última en el estuario del Río de la Plata (ERLP).

En latitudes medias y altas, los litorales estuarinos están dominados por vegetación herbácea, formando lo que comúnmente se conoce como marismas. Representan ambientes intermareales que se desarrollan en sitios protegidos de la alta energía de las olas, donde se facilita el depósito de sedimento fino y el crecimiento de plantas vasculares (Isacch et al., 2010), encontrándose asociadas a planicies de marea, que constituyen la transición hacia el ambiente acuático.

En la costa de la zona interna (delta del Paraná hasta la línea imaginaria que une Punta Lara -Argentina- y Colonia -Uruguay-) e intermedia del ERLP (línea que une Punta Piedras y Montevideo) (Fig. 1) predominan las marismas de agua dulce, y en la zona externa (hasta el eje Punta Rasa-Punta del Este) se desarrollan marismas con un mayor grado de salinidad. Mientras que las primeras han sido fuertemente modificadas en la Región Metropolitana de Buenos Aires, las segundas, desarrolladas principalmente a lo largo de la Bahía Samborombón, han sido medianamente transformadas. Allí, la ganadería extensiva, la minería en cordones conchiles y las canalizaciones asociadas al tramo inferior de la cuenca del río Salado (Carol et al., 2013), coexisten con parches de vegetación autóctona.

Si bien existe abundante literatura acerca de los procesos de transformaciones costeras como resultado de las interrelaciones entre los componentes hidrológicos, bióticos, sedimentarios y antrópicos que afectan a las marismas costeras de agua salada (Temmerman et al., 2007; McLoughlin et al., 2015; Leonardi et al., 2016), las marismas de agua dulce han sido menos estudiadas (Baldwin, 2009), concentrándose las investigaciones en América del Norte y Europa (Odum, 1988; Meire y Vincx, 1993; Mitsch y Gosselink, 2000). En cuanto al ERLP, existen escasos registros bibliográficos, predominando los estudios acerca de la ecología en marismas en el delta del río Paraná (Kandus y Malvarez, 2004; Pratolongo et al., 2007; Kalesnik et al., 2008, 2011; Medina y Codignotto, 2013) y la modificación de las mismas por las dinámicas urbanas relativas a la Región Metropolitana de Buenos Aires (López y Marcomini, 2004). Asimismo, se han desarrollado estudios que utilizan metodologías similares a las propuestas por el presente trabajo en las costas del área intermedia y externa del estuario (Bértola et al., 1993; Bértola, 1994; Dalmau, 1996; Kokot y Guerrieri, 2005; Lamaro et al., 2009; Codignotto et al., 2011, 2012; D'Amico et al., 2016; Cellone et al., 2016). 


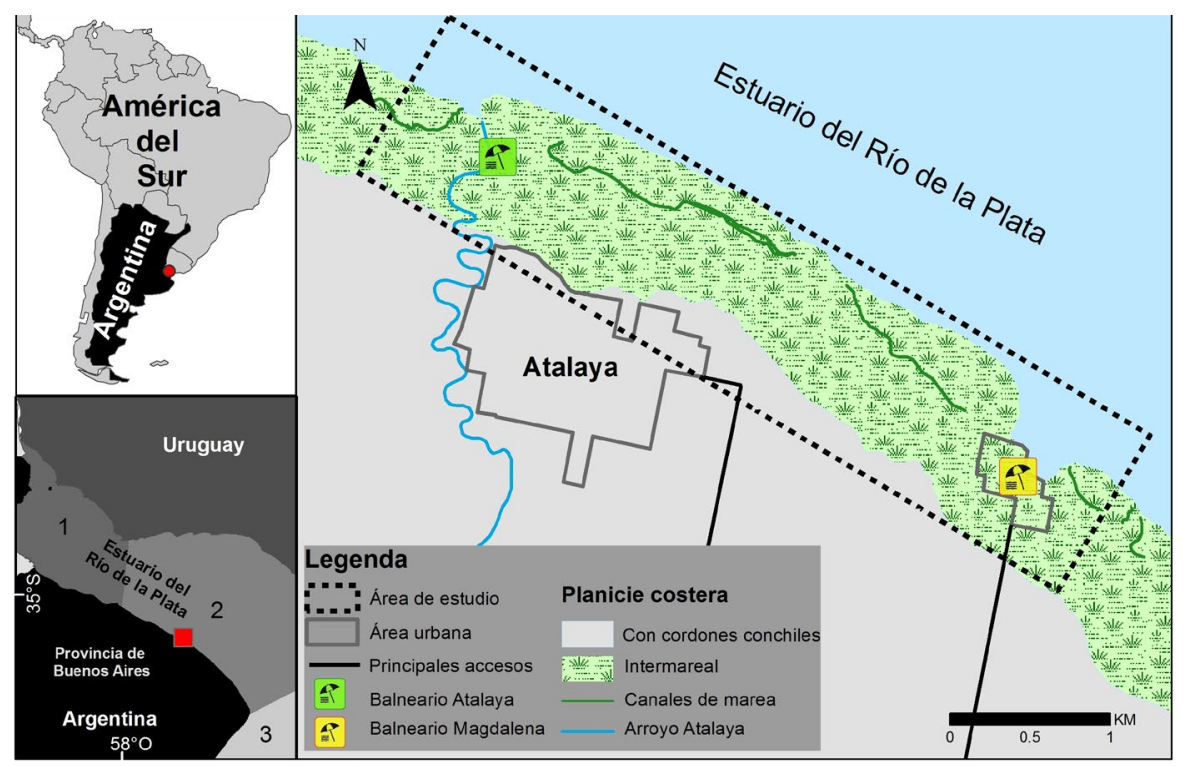

Figura 1. Localización del área de estudio y zonificación del ERLP: 1: Interna; 2: Intermedia; 3: Externa. Fuente: Límites jurisdiccionales: Porto Tapiquén (2015), Instituto de Estadísticas de Uruguay e Instituto Geográfico Nacional.

En el presente estudio se propone un análisis multitemporal de la costa de Punta Atalaya (partido de Magdalena, Buenos Aires), situada en el sector intermedio de la costa del ERLP, utilizando la línea de costa como indicador. La reconstrucción de la misma para años seleccionados en el periodo 1929-2016 se ha realizado a partir de su identificación en fotografías aéreas e imágenes de satélite de alta resolución. Mediante la utilización de un software especializado en el análisis multitemporal de cambios, inspección en campo y análisis de bibliografía general y específica, se realizó una aproximación explicativa al entendimiento de la dinámica litoral de esta franja territorial de formación reciente.

\section{El estuario del Río de la Plata: un complejo espacio dinámico}

\subsection{El estuario rioplatense y su estudio}

El ERLP constituye la porción final de la gran cuenca del Plata, y posee una extensión aproximada de $300 \mathrm{~km}$, un ancho variable entre 32 y $230 \mathrm{~km}$ (Píccolo y Perillo, 1997), y una superficie de $38.000 \mathrm{~km}^{2}$ (Wells y Daborn, 1998). Se extiende desde el delta del Paraná hasta la línea imaginaria que une Punta Rasa (Argentina) con Punta del Este (Uruguay) (Fig. 1).

Una caracterización de los estudios realizados acerca de las dinámicas que operan en el estuario revela la amplia cantidad de datos analizados desde mediados del siglo 
XX. Inicialmente, Tossini (1959) enfatizó en el análisis de parámetros de la cuenca continental del Plata, aunque no sobre el estuario. Durante la década de 1960 el Servicio de Hidrografía Naval de Argentina encabezó estudios de parámetros cuantitativos. En particular, se analizaron las interacciones mar-atmósfera en cuanto a la dinámica meteorológica, los regímenes y corrientes de marea y su relación con las crecidas históricas (Balay, 1961), y las dinámicas hidrográficas y sedimentarias (Urien, 1966, 1972). La rigurosidad de dichas investigaciones tiene su correlato en el uso actual de los datos obtenidos.

Posteriormente, dos acontecimientos marcaron la elaboración de una sucesión de investigaciones sobre el estuario, atendiendo al componente binacional en la jurisdicción del mismo: la firma del Tratado del Río de la Plata en 1972 y la creación de la Comisión Administradora del Río de la Plata en 1976. A raíz de ello, se iniciaron en 1981 investigaciones dirigidas por el Instituto Nacional de Investigación y Desarrollo Pesquero de Mar del Plata acerca de parámetros relacionados con esta actividad. Hacia fines de siglo XX, el proyecto FREPLATA realizó campañas de recolección de datos sobre contaminación acuática y biodiversidad, especialmente asociada a la actividad pesquera. Por otra parte, el Centro de Investigaciones para la Dinámica del Mar y la Atmósfera, creado en 1987 por convenio entre la Universidad de Buenos Aires y el Centro de Investigaciones Científicas de la Provincia de Buenos Aires, e incorporado al Consejo de Investigaciones Científicas y Técnicas desde 1995, ha estudiado procesos físicos asociados al sistema agua-tierra-atmósfera en el ERLP y el mar argentino, analizando datos a partir de modelados matemáticos.

La influencia del paradigma científico neopositivista es notable en el sesgo sistémico de los trabajos mencionados. La inicial recolección de datos empíricos permitió, con las técnicas de modelado matemático en la década de 1980, comprender la interacción entre parámetros climáticos e hidrológicos. En particular, los estudios sobre geomorfología de costas han abogado por teorías dentro del paradigma de equilibrio, elaborando múltiples modelos predictivos (Davidson-Amott, 2010).

Sin embargo, la crisis ambiental de la década de 1970 indujo cambios en la concepción de equilibrio ecosistémico, migrando hacia una noción de no-equilibrio. Este nuevo paradigma, que se desarrolló fuertemente en las ciencias biológicas y en la ecología en particular, incorporó a la sociedad como parte del ecosistema (Pickett y McDonell, 1993; Fiedler et al., 1997).

Siguiendo este planteamiento, y lejos de representar un sistema cerrado (Boschi, 1987), las distintas zonas en las que se ha dividido el estuario con fines analíticos presentan una marcada interacción, que conduce a procesos no lineales, donde las nociones de dinamismo y cambio, orientados por la estocasticidad y el caos, son los supuestos dominantes (Sarmiento, 2001). En particular, las costas estuarinas son espacios donde los flujos de materia y energía suceden en diferentes escalas espacio-temporales. Los espacios costeros pueden acusar, en el corto plazo, importantes transformaciones en sus formas litorales.

\subsection{El estuario rioplatense como espacio de flujos}

Entre los factores que introducen flujos de energía al estuario, las mareas, los vientos y las corrientes de descarga y de deriva litoral son determinantes de cambios en los 
flujos sedimentarios. En cuanto a las mareas, factores astronómicos y meteorológicos determinan un régimen mareal semidiurno, con desigualdades diurnas, siendo el componente lunar el dominante (Wells y Daborn, 1998). Su comportamiento es modificado por el viento, el efecto Coriolis que desvía las aguas hacia el oeste (costa argentina), y la profundidad y ancho del estuario, lo que provoca que la altura de la marea aumente a medida que se interna en el mismo (Wells, 1995; Nagy et al., 1998). Las mareas ordinarias poseen pequeña amplitud $(0,46 / 0,52 \mathrm{~m})$, correspondiendo a un régimen micromareal (Wells, 1995).

El oleaje en el ERLP medio y superior responde principalmente a vientos locales. La altura y periodo promedio en el estuario interior (mediciones realizadas en Costanera Sur, Buenos Aires) es de 0,2 a 0,6 m, siendo improbables olas de más de 1,5 m (Simionato et al., 2011) y de 3 a 4 s de periodo. En el estuario exterior, los valores oscilan entre 0,5 a $1 \mathrm{~m}$ y de $10 \mathrm{~s}$. Las olas de tormentas son poco frecuentes, presentando una altura estimada en 3 m (Canziani et al., 2013). Los vientos provenientes del ámbito oceánico se disipan rápidamente al internarse en el estuario por la baja profundidad (Tomazín y Cáceres, 2014), al contrario de lo que sucede con los provenientes del sudeste, si presentan la intensidad suficiente. A pesar de la escasa recurrencia del oleaje extremo, su ocurrencia es clave ya que eventos de alta energía son capaces de reconfigurar la dinámica sedimentaria costera.

En eventos de tiempo severo pueden desarrollarse ondas de tormenta (ODT), propiciando la acumulación de aguas sobre la costa e intensificando el efecto de las mareas y el oleaje. Las ODT positivas (cuando el nivel del río aumenta sobre el valor estimado de mareas) suelen estar asociadas al fenómeno de sudestadas, fuertes y persistentes vientos del SE que elevan el nivel medio del río, siendo más frecuentes en verano (Bischoff, 2005), o a la irrupción de aire frío proveniente del sur (Dragani et al., 2013). Según la persistencia del viento, la sudestada puede durar dos o tres días, afectando mayormente las regiones bajas, con riesgo de inundarlas.

Los flujos de descarga, provenientes del gran aporte fluvial de la cuenca, y los fuertes oleajes provenientes del SE motorizan dos corrientes sedimentarias, la de descarga y la de deriva litoral. La primera, de sentido NO-SE, depende de las descargas del río Paraná $\left(17.000 \mathrm{~m}^{3} / \mathrm{s}\right)$ y el Uruguay $\left(5450 \mathrm{~m}^{3} / \mathrm{s}\right)$ (Nagy et al., 1998). De norte a sur, los ríos Luján, Riachuelo, Samborombón, Salado y San Clemente, canales de la Bahía Samborombón y otros arroyos, hacen su aporte en menor medida desde la margen argentina. Esta misma corriente transporta sedimentos limos arcillosos en suspensión, que fluyen hacia la boca del estuario a unos $700 \mathrm{u} 800 \mathrm{~m}$ de la costa.

Asimismo, en las sudestadas se produce una circulación de sedimentos más gruesos, limo-arenosos, en sentido contrario (SE-NO) (López y Marcomini, 2011). La incidencia del oleaje con un ángulo agudo sobre la costa motoriza mecanismos de deriva litoral, a partir de erosión, transporte y depositación de sedimentos. Ésta es evidenciada en la acumulación al sur de estructuras costeras y en la curvatura actual hacia el norte de la boca de la mayoría de los cursos de agua (Codignotto y Kokot, 2005). En eventos de viento NE la dirección de la deriva litoral puede revertirse (Kokot y Guerrieri, 2005). 
Los sedimentos acumulados progresivamente en la zona litoral son removilizados durante los eventos de fuerte oleaje y depositados en la playa conformando barras paralelas, quedando expuestos o no de acuerdo a la altura de las mareas (Codignotto y Kokot, 2005).

\section{3. Área de estudio}

La costa del litoral rioplatense en su margen argentina es de formación geológica reciente. Se encuentra desarrollada sobre la Llanura Costera (Cavallotto, 1995) (ver Fig. 1), constituyendo una costa regresiva formada luego del último máximo holoceno ocurrido hace 6000 años (Cavallotto, 2002). El límite de este máximo está representado por un micro acantilado (cota aproximada de 5 m s.n.m.), que separa la Llanura Costera de la unidad geomorfológica de Llanura Continental.

Sobre un sustrato plio-pleistoceno se desarrolló por progradación acompañando el último ciclo de descenso del nivel del mar. Inicialmente se formaron llanuras de mareas que fueron progresivamente encerradas por cordones de playa, que migraron en dirección SE-NO en el sentido de la deriva litoral. Este mecanismo dio lugar la formación de una costa sinuosa, con una serie de salientes y entrantes, siendo las primeras denominadas puntas. Hacia los 2-2,5 ka AP, las condiciones marinas migraron a estuarinas, conformándose la subunidad de planicie costera intermareal (Melo et al., 2013), aquí estudiada.

El presente trabajo analiza el sector de Punta Atalaya, localizada en la costa del partido de Magdalena, en la zona intermedia del ERLP en su margen argentina (Fig. 1). La localidad homónima se emplaza en las cercanías de esta punta, conformando un poblado de 720 habitantes (INDEC, 2010) dispuesto sobre un cordón conchil (altura máxima de 5 m s.n.m.). El mismo surgió a partir de la valoración del arroyo Atalaya o Buñirigo como puerto a fines del siglo XIX. El arroyo presenta un diseño meandriforme, rectificado por tramos producto de la baja pendiente del terreno, y discurre por la Llanura Costera hasta llegar a las aguas del estuario.

\section{Materiales y métodos}

Para efectuar un análisis multitemporal de la evolución de la línea de costa del área de estudio, se trabajó con fotografías aéreas e imágenes de satélite de alta resolución de los años 1929, 1959, 1968, 1972, 1985, 1991, 2002, 2013 y 2016 (Tabla 1). La discontinuidad en los años de adquisición de las fotografías aéreas se debe a que el registro de las mismas depende de diferentes organismos (fuentes en Tabla 1). Complementariamente, se seleccionaron tres cortes temporales de imágenes de satélite Quickbird descargadas desde el software Google Earth. Las imágenes fueron georreferenciadas en el sistema WGS84/ UTM21S utilizando un número variable de puntos de control de la imagen de satélite Quickbird 2013 (Ford, 2012; Frankl et al., 2013) complementados por puntos GPS adquiridos en campo. Los mismos corresponden a elementos antrópicos estables en el tiempo, tales como edificaciones, vías de comunicación e intersecciones de alambrados. 
Tabla 1. Imágenes utilizadas para el análisis multitemporal de la línea de costa según año, escala y fuente y error total de digitalización calculado.

\begin{tabular}{|c|c|c|c|c|}
\hline Año & Escala & $\begin{array}{c}\text { Error Medio } \\
\text { Cuadrático (m)* }\end{array}$ & $\begin{array}{c}\text { Error total de } \\
\text { digitalización (m) }\end{array}$ & Fuente \\
\hline $\mathbf{1 9 2 9}$ & $1: 5000$ & 2,48 & 5.39 & Base Aeronaval Punta Indio \\
\hline $\mathbf{1 9 5 9}$ & $1: 25000$ & 1,71 & 5.48 & Base Aeronaval Punta Indio \\
\hline $\mathbf{1 9 6 8}$ & $1: 10000$ & 0,93 & 3.31 & Geodesia Buenos Aires \\
\hline $\mathbf{1 9 7 2}$ & $1: 10000$ & 0,44 & 3.37 & Geodesia Buenos Aires \\
\hline $\mathbf{1 9 8 5}$ & $1: 10000$ & 0,86 & 2.54 & Geodesia Buenos Aires \\
\hline $\mathbf{1 9 9 1}$ & $1: 20000$ & 0,78 & 3.73 & Servicio de Hidrografía Naval \\
\hline $\mathbf{2 0 0 2}$ & $1: 10000$ & 0,01 & 1.89 & Google Earth \\
\hline $\mathbf{2 0 1 3}$ & $1: 10000$ & & 1.83 & Google Earth \\
\hline $\mathbf{2 0 1 6}$ & $1: 10000$ & 0,46 & 2.26 & Google Earth \\
\hline
\end{tabular}

*Mayor error medio cuadrático para una imagen dentro del mosaico.

Para efectuar el análisis cuantitativo de la variación multitemporal de la línea de costa, se utilizaron las herramientas provistas por el Digital Shoreline Analyst System (DSAS) (Thieler et al., 2009), extensión elaborada para su funcionamiento en ArcGis por el Servicio Geológico de Estados Unidos. DSAS permite calcular tasas de cambio a partir de diferentes estadísticas utilizando las líneas de costa digitalizadas, una línea de base paralela a las anteriores, y transectos que intersectan normalmente a las líneas de costa (cada 10 metros en el presente trabajo) (Fig. 2).

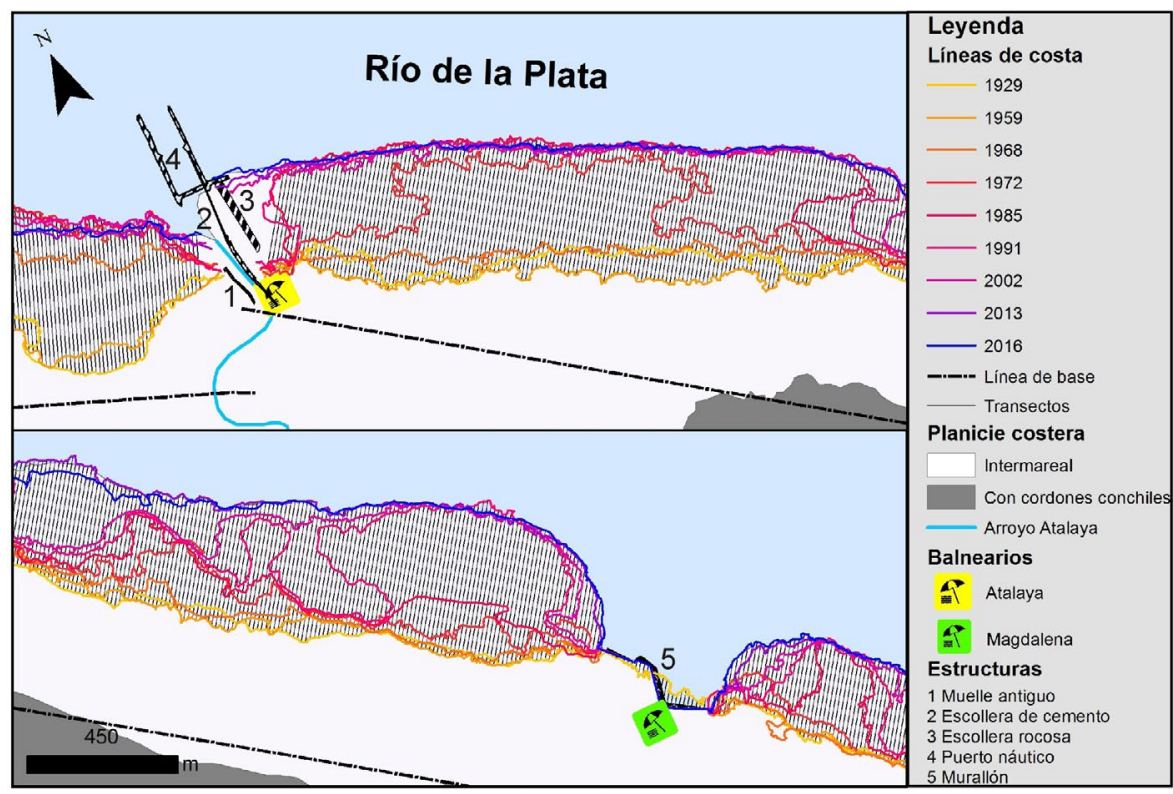

Figura 2. Líneas de costa para los años 1929-2016, balnearios y estructuras costeras. En el recuadro A se observan los transectos elaborados con el programa DSAS. Imagen satelital base: Digital Globe, 2016. 
Existen diversos indicadores o proxies para definir la línea de costa, distinguiéndose entre aquellos discernibles visualmente y los que utilizan datos de marea (Boak y Turner, 2005). Entre los primeros, la línea de marea alta, el pie de médano o acantilado, las crestas de playa, y el borde de vegetación costera son algunos de los más utilizados. Éste último indicador fue seleccionado ya que resulta ser más estable que el relativo a identificar la línea de pleamar para un estudio a largo plazo (Hoeke et al., 2001; Cellone et al., 2016), además de no contar en todos los casos con la fecha exacta de toma de las fotografías aéreas. Se digitalizó la línea de costa manualmente a una escala de detalle constante, mayor a 1:1000. El sector de la desembocadura del arroyo Atalaya no fue digitalizado debido a la presencia de infraestructura portuaria que podría introducir diferencias a la hora de la cuantificación del avance o retroceso en la línea de costa. Sin embargo, la influencia de las estructuras es analizada cualitativamente de manera complementaria.

Entre las fuentes de error en la digitalización de las líneas de costa, Fletcher et al. (2003) identifican los relativos a la posición y a las mediciones. Los primeros derivan de las diferencias introducidas por la marea, las variaciones estacionales y los cambios por fenómenos como tormentas. Los segundos son los vinculados a la digitalización por el o los operadores, y el error medio cuadrático resultante de la georreferenciación de las imágenes.

El error total de digitalización (Tabla 1) fue estimado para cada periodo como resultado de la suma de los cuadrados del error derivado del píxel de las imágenes, el de digitalización y el de rectificación (Ford, 2012; Cellone et al., 2016). Este último depende del valor de RMS (Root Mean Square o media cuadrática) de cada imagen georreferenciada, promediado en el caso de los mosaicos de imagen (Ford, 2012). El error de digitalización (realizada por un solo operador) se consideró con el valor de 1 .

Para cuantificar los cambios del análisis multitemporal, DSAS permite obtener distintas estadísticas, dos de ellas computando distancias entre un par de líneas, y cuatro que obtienen tasas de cambio por medio de diferentes algoritmos. Para estimar la variación en metros lineales totales se escogió la estadística de Cambio Neto (Net Shoreline Movement-NSM-), que permite calcular la distancia total en la unidad de medida asignada entre la línea de costa más antigua y la más moderna. Para estimar la tasa de cambio en metros por año, se eligió la Regresión Lineal Ponderada (Weighted Linear Regression -WLR-), donde a los datos más fiables, en los que la incertidumbre de la posición es menor, se les otorga mayor énfasis o peso para determinar una línea de mejor ajuste (Thieler et al., 2009).

Finalmente, se complementó el análisis anterior con bibliografía específica y se realizó una inspección in situ de la vegetación, las unidades geomorfológicas y las materialidades antrópicas presentes en campo.

\section{Resultados}

\subsection{Análisis multitemporal de la línea de costa}

El análisis multitemporal permitió diferenciar el proceso de progradación costera en dos etapas: 1929-1968 y 1968-2016. 
En la primera (Fig. 3), la zona localizada al norte del balneario de Atalaya presentó una notable acreción, con un NSM que oscila entre 8,29 y 293 m, y un WLR entre 0,97 y 5,36 m/año, localizándose los valores de forma tal que puede distinguirse acreción y desaparición de una pequeña bahía al NO del arroyo Atalaya. El aporte sedimentario del cercano arroyo homónimo, direccionado por deriva litoral hacia el NO, puede ser el responsable de este proceso. Sin embargo, en 1959 se registró un retroceso de la línea de costa en algunos sectores, probablemente relacionado a un evento de sudestada en el año 1958 (Re et al., 2015), donde el nivel medio del río superó los 3 m por encima del nivel del Riachuelo de la Ciudad Autónoma de Buenos Aires.

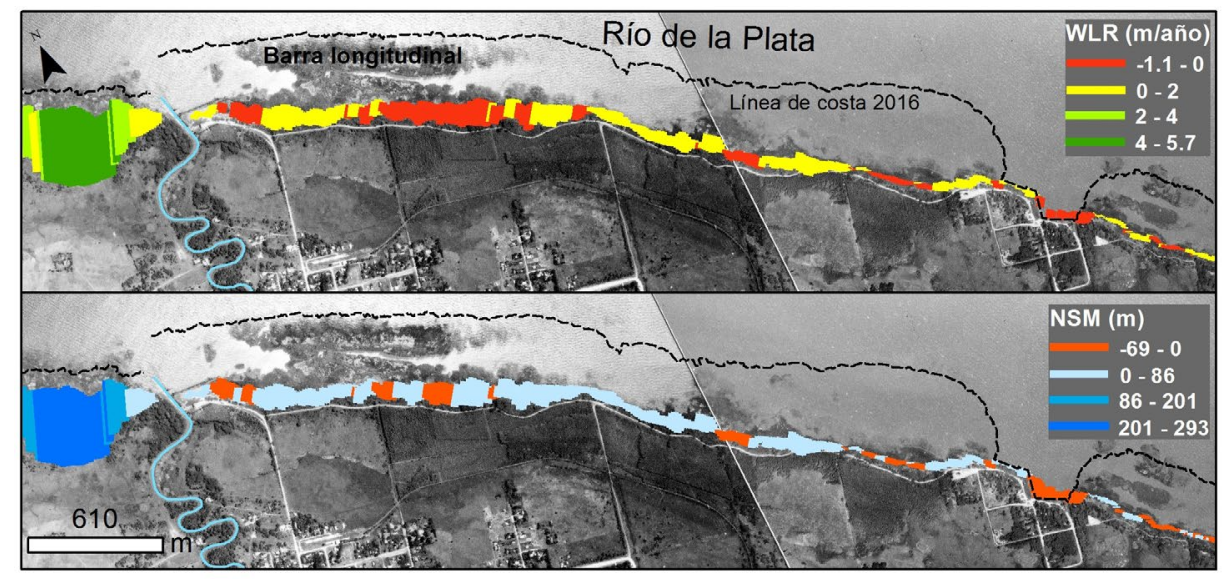

Figura 3. Valores WLR y NSM para el periodo 1929-1968. Fuente: Fotografía aérea base: Base Aeronaval Punta Indio, 1972.

Hacia el sur de este balneario, se registraron alternancias entre acreción y erosión en micro-escala, siendo el NSM entre 86,3 y -69,2 y el WLR de -1,94 y 1,93 m/año. En el balneario municipal de Magdalena hubo erosión en función de que se construyó un murallón para la protección del mismo en la década de 1940. El resto de las zonas que presentan erosión para el periodo se disponen alternadas entre zonas que registran acreción. Esta última pudo desarrollarse puntualmente en respuesta a factores locales, vinculados a la ausencia de vegetación y/o a la disponibilidad de sedimentos escasamente consolidados.

La Figura 3 presenta los valores analizados, dispuestos sobre la foto aérea de 1972, donde la formación de una barra longitudinal delante de la línea de costa anterior, al sur del balneario municipal de Atalaya, comenzó a distinguirse. Hacia el sur del balneario de Magdalena se observó también acreción a modo de parches longitudinales cercanos a la costa.

La segunda etapa, comprendida entre 1968 y 2016, posee los valores de avance de la línea de costa hacia el estuario más destacados. En las fechas siguientes a 1968 se ob- 
serva el avance de la línea y la consolidación del cordón costero, a partir del asentamiento de vegetación en los distintos subambientes. Los máximos valores NSM para el total del periodo considerado alcanzan hasta $360 \mathrm{~m}$ lineales, registrando erosión sólo para la zona del balneario de Magdalena en función de la refracción ejercida por el murallón costero, como se explicará en adelante.

\subsection{Estructuras costeras y procesos sedimentarios}

El arroyo Atalaya ha sido históricamente valorado por su factibilidad portuaria. Desde fines del siglo XIX, distintas estructuras se construyeron para el aprovechamiento del mismo como vía navegable y sitio de resguardo de embarcaciones. El análisis de las mismas da cuenta del aporte sedimentario del arroyo y la acción de la deriva litoral.

La primera estructura consistió en dos muelles de madera dispuestos a ambos lados del arroyo para efectuar la carga de tasajo hacia fines del siglo XIX e inicios del siglo $\mathrm{XX}$, en función de los saladeros localizados en las cercanías (Fig. 4A). Los muelles, hoy situados en la desembocadura del arroyo, se internaban varios metros en el río, dando cuenta de la antigua localización de la línea de costa.

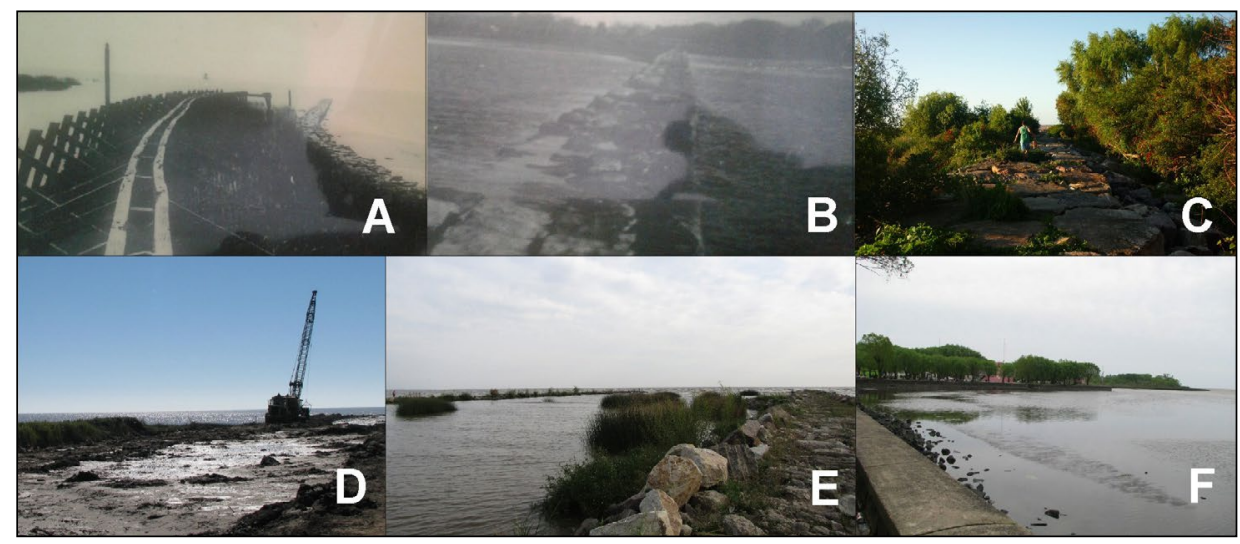

Figura 4. Estructuras costeras. A: Restos del muelle utilizado por las embarcaciones saladeriles a fines del s XIX, y a continuación del mismo escollera construida en 1952; B: detalle de esa escollera; C: escollera de piedra partida construida en 1998, hoy desmantelada, vegetación en zonas acrecionadas a sus márgenes en 2012.; D: Estructuras del puerto náutico en construcción, 2011 y E, en la actualidad; F: murallón del balneario público de Magdalena. Fuentes: A y B, Museo Histórico de Atalaya.

El ingeniero Figueroa (1898) destacó para fines del siglo XIX la necesidad de dragado y eventual protección del canal portuario con defensas de piedra y arcilla, lo cual permitiría además encauzar las corrientes de flujo y reflujo de la marea, aunque esta recomendación nunca se concretó. El escaso mantenimiento del dragado y la estructura permeable del muelle llevaron paulatinamente a la sedimentación parcial de la desembocadura. 
Hacia 1952 se construyó una escollera de bolsas de cemento fraguable en agua con el objeto de proteger la desembocadura de las corrientes de deriva, para permitir el ingreso de pequeñas embarcaciones (Fig. 4B). Aunque esta actividad portuaria fue efímera, la estructura sentó las bases para una posterior escollera de roca partida en 1998 (Fig. 4C). En función de la decisión estatal de crear un puerto deportivo, fue reutilizada para construir una nueva estructura en 2004, emplazada predominantemente offshore (Fig. 4D y E).

De todas las estructuras anteriores, la escollera actual ha sido la única capaz de establecer un efecto acrecional significante, al oficiar como verdadero obstáculo a la circulación sedimentaria relacionada con la deriva litoral, evidenciada en la curvatura hacia el noroeste de las barras longitudinales cerca de la costa. De manera similar, en Isla Paulino (Puerto La Plata) al norte del área de estudio, el inicial tablestacado y la actual escollera portuaria han desencadenado un proceso acrecional desde fines del siglo XIX (D'Amico et al., 2018).

Por otra parte, en la década 1940 se construyó en Magdalena un murallón para defender la costa del oleaje, a los fines de la creación de un balneario público. El mismo presenta una estructura vertical de rocas y hormigón de más de dos metros de alto con respecto al nivel de base en marea baja, y sólo es alcanzado por las aguas en pleamar (Fig. 4F). Al pie del murallón, se colocaron rocas partidas para proteger su base del embate de las olas. Este tipo de estructuras costeras absorben escasa energía del oleaje, y por lo tanto, reflejan gran parte de la misma (Isla, 2006). Debido a ello, el sector adyacente al murallón presenta una dinámica de flujo y reflujo de mayor energía, no propiciando el desarrollo de juncales o de otro tipo de vegetación intermareal.

\subsection{Estabilización de cordones costeros y formación de nuevos humedales}

La dinámica de formación de cordones costeros y espigas, y la constitución de ambientes de humedal entre éstos y el continente es un fenómeno que se reitera en las costas del Río de la Plata en su historia geológica reciente. La hipótesis más estudiada refiere a la formación de humedales o pequeñas ensenadas asociada a la migración de sedimentos por efecto de la deriva litoral, que tracciona los mismos en sentido NO paralelo a la costa. La formación de Punta Blanca y de la ensenada de Barragán, hacia el norte del área de estudio, estuvo vinculada a estos procesos (Cavallotto, 1995; Fucks et al., 2014).

En base al análisis realizado en el presente trabajo, se propone una hipótesis alternativa. Paralelas a la línea de costa, se desarrollan barras longitudinales (crestas y canaletas, o ridges and runnels) en la zona intermareal y submareal, de hasta 30 metros de ancho, claramente discernibles durante la marea baja (Fig. 5A y B). Su constitución en costas micromareales está relacionada a la erosión de sedimentos durante las tormentas y la formación de barras de acreción (Dabrio, 1982). Durante periodos de calma, las barras migran lentamente hacia la costa, pudiendo incrementar su altura hasta quedar atmosféricamente expuestas, formando nuevas bermas. 


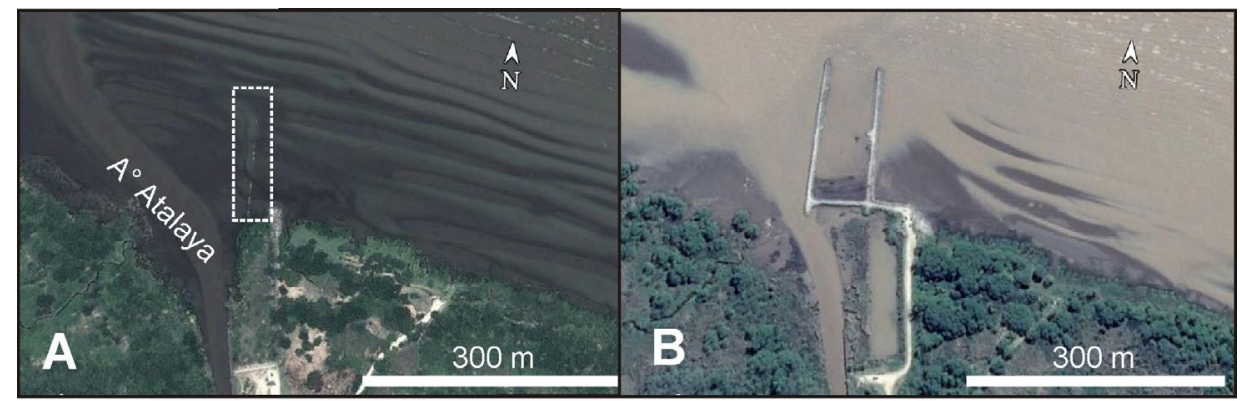

Figura 5. Barras longitudinales en la desembocadura del Arroyo Atalaya. A: Antes de la escollera del puerto deportivo, en 2010, se distingue la escollera de 1952 (en el rectángulo punteado blanco). B: Dos años después de la construcción de la escollera SE del puerto deportivo, en 2016. Fuente: Digital Globe, Google Earth.

La acreción vertical de una barra longitudinal, que logró quedar expuesta en marea alta, comenzó a actuar como obstáculo ralentizando la energía del oleaje, permitiendo la formación de un área de humedal entre la barra y la línea de costa anterior correspondiente a un cordón costero más antiguo. En la Figura 6, los valores más elevados de WLR se corresponden con sectores costeros cuya acreción es reciente en comparación a todo el periodo, es decir, que se formaron rápidamente con posterioridad al año 1985, siguiendo el mecanismo acrecional descrito. El WRL de estos sectores para todo el periodo es de 4 a 6 m/año, mientras que en la etapa 1 (1929-1968), el valor oscila entre 0 y $4 \mathrm{~m} /$ año.

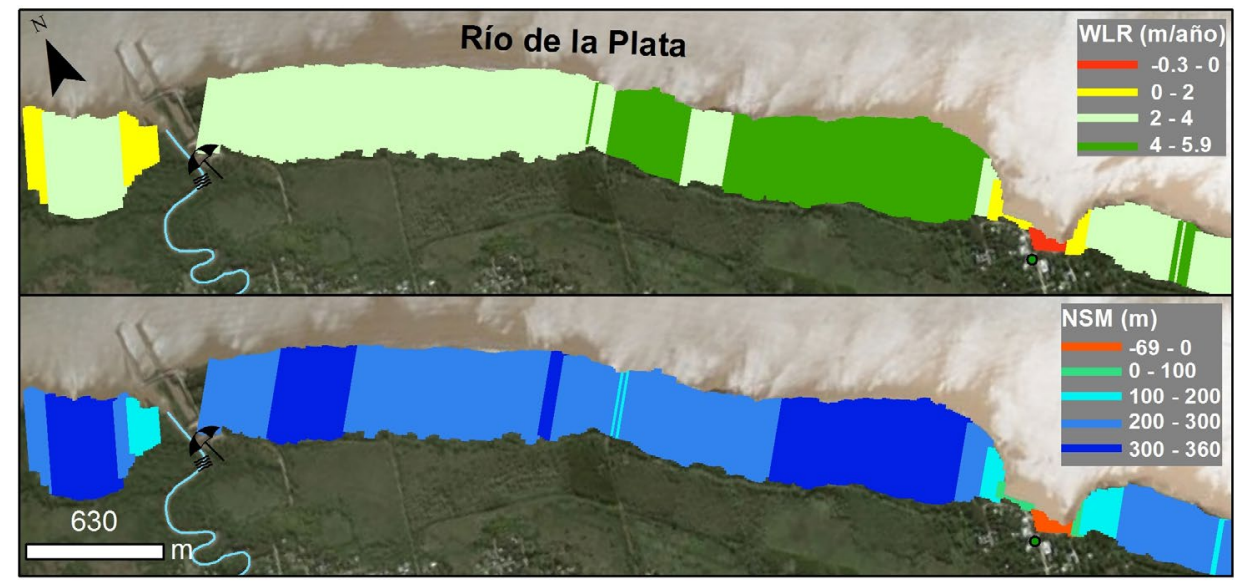

Figura 6. Valores WLR y NSM para el periodo 1929-2016. Fuente: Imagen satelital base: Digital Globe, 2016.

La nueva costa acrecionada presenta una serie de subambientes asociados a la formación de cordones costeros y humedales interiores, donde los pulsos de agua del estua- 
rio actúan de manera diferencial de acuerdo a su topografía, conformando condiciones propicias para el desarrollo de determinadas especies vegetales.

En la planicie intermareal del área de estudio, sobre sustrato areno-arcilloso y en sucesión hacia el continente se pudieron identificar, a partir del método de claves de especies (Lahitte y Hurrel, 1997), comunidades de juncales costeros, integrados por Scirpus americanus, Schoenoplectus californicus y Eleocharis, asociados con gramíneas como Paspalum vaginatum Sw. y Panicum decipiens Nees, descritas también para zonas cercanas como el Balneario La Balandra por Passarelli et al. (2014) (Fig. 7A-C, H, I). El césped ribereño crece en zonas de altitud levemente mayor pero bajo el influjo mareal esporádico (Fig. 7B y D), con especies como Gomphrena elegans, Hydrocotyle ranunculoides, Cardamine bonariensis y Cardamine hirsuta. En la zona supramareal, sólo afectada en eventos extremos como mareas en sicigias o tormentas, especies nativas, leñosas e higrófilas, como Salix humboldtiana (sauce criollo), Erythrina crista-galli (ceibo) y Tessaria integrifolia (aliso de río) se asientan sobre el cordón costero (Fig. 7A, B y F). Las semillas de éstas y otras especies son transportadas en suspensión por la corriente y por el viento.

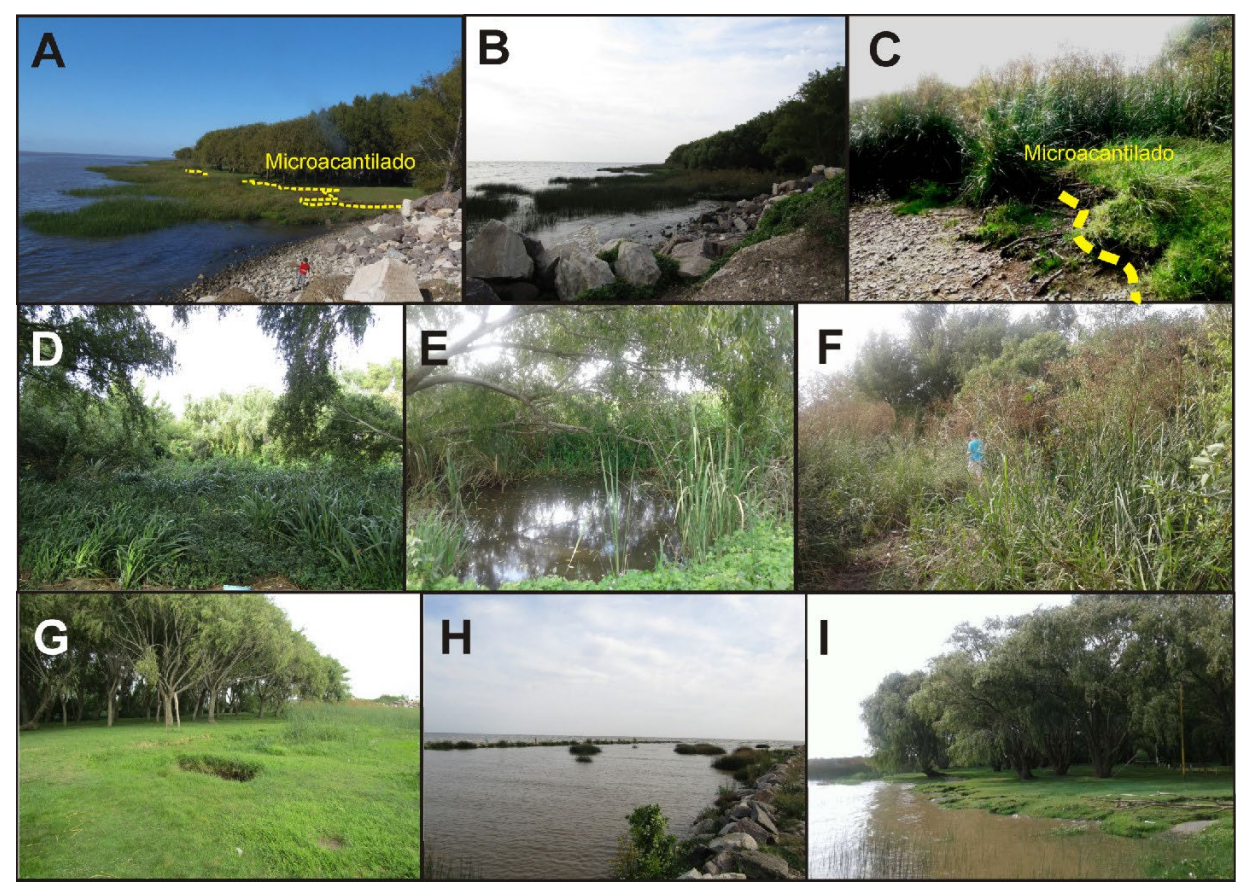

Figura 7. Detalle de sectores de la costa entre los balnearios de Atalaya y Magdalena: $A, B$ y C: Costa al sur de la escollera del puerto deportivo en 2015 (A) y 2018 (B y C); D y E: Sector del humedal costero; F: Vegetación sobre cordón costero; G: Césped ribereño y sauzales sobre cordón costero; H: Dársena de puerto deportivo; I:Balneario municipal de Magdalena.

El sector acrecionado alberga en su interior un humedal de agua dulce, colonizado por especies de pajonal mixto como la invasora Iris pseudacorus L. (lirio amarillo) y las 
nativas Eryngium pandanifolium e Ipomoea indica, con presencia de canales de marea de diferentes longitudes que lo alimentan (Fig. 7D y E).

La construcción de infraestructura náutica y de caminos para el acceso al río ha desarticulado paulatinamente los ambientes de humedal de formación reciente. Por ejemplo, previo a la construcción del espigón rocoso y las escolleras del puerto náutico un canal de marea alimentaba el sector de humedal inmediatamente al sur del balneario atalayense, siendo éste seccionado a partir de la construcción de esa infraestructura, facilitando la colmatación progresiva al cercenar la entrada de pulsos de agua.

Este humedal aún no posee categorías de protección ambiental que consideren su funcionamiento sistémico. La actual categoría de Refugio de Vida Silvestre que abarca la zona (Ley Provincial $N^{\circ} 12.016$ ) sólo protege la fauna autóctona. Sin embargo, desde el Plan Estratégico de Magdalena 2016-2040 se propone la ampliación de la Reserva de Biósfera Parque Costero del Sur, lo cual contemplaría el área de estudio. Los objetivos de esta reserva buscan compatibilizar la conservación de los recursos naturales con el uso sustentable de los mismos (Decreto Provincial 7585/1994).

\section{Discusión}

La interacción entre las fuerzas hidrodinámicas, los sedimentos, la vegetación y las estructuras antrópicas a escala local son procesos claves y complejos en la modelación de las marismas. Las retroalimentaciones positivas y negativas entre estos componentes dan cuenta de un ecosistema que no se encuentra en equilibrio, sino que es modificado constantemente en respuesta a múltiples factores.

El rol de la vegetación en la consolidación de estos ambientes es clave y a la vez discutido. En cuanto a la planicie intermareal, la especie Schoenoplectus californicus, históricamente valorada por los junqueros de la zona para la confección de artesanías (Stampella et al., 2016) es pionera en términos ecosistémicos. Al expandirse mediante sus rizomas, genera un entramado que puede favorecer la sedimentación, actuando como sustrato para especies leñosas, contribuyendo al filtrado de nutrientes y depurando las aguas (Kalesnik, 2011). En condiciones regulares de marea, el flujo de agua estimula el desarrollo de varias yemas de juncos simultáneamente, y al ser sus tallos flexibles pero resistentes, actúan como un verdadero "peine" para la retención de sedimento (Fig. 8), ralentizando la energía del oleaje (Yapp et al., 1917; van de Koppel et al., 2005). Además, la alteración en la conformación del suelo por el aporte de detritos y sedimentos finos de la vegetación, puede aumentar la cohesividad de las partículas edáficas, mitigando la erosión (Feagin et al., 2009). Sin embargo, la retroalimentación puede volverse negativa cuando las estructuras vegetales, al divergir los flujos de agua, incrementan las velocidades del flujo, pudiendo desarrollar la erosión (Bouma et al., 2009). Los factores erosivos pueden desencadenar pérdida de vegetación, formación de micro acantilados, similares a los observados por Yapp et al. (1917), Allen (2000) y van de Koppel et al. (2005) en marismas del hemisferio norte, y retroceso de la línea de costa, incluso ante la ausencia de factores externos de alta energía. Las terrazas interiores pueden ser consideradas maduras y más estables, mientras que las inferiores, cercanas al borde del agua, 
suelen estar en un estadio inicial, aunque reporten mayores ritmos de acreción (Allen, 2000). Paralelamente, la erosión de la base del acantilado puede eventualmente provocar la caída del borde superior del mismo, suavizando su perfil. En otros casos, se ha reportado la existencia de acantilados remanentes del proceso erosivo (Allen, 2000).

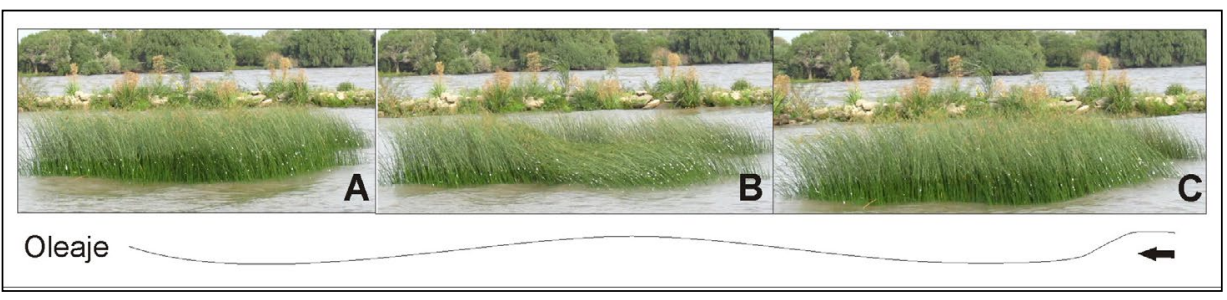

Figura 8. Comportamiento del junco frente al oleaje en Atalaya, secuencia temporal A, B, C y dirección del mismo indicada con flecha. Imágenes del 11/4/2018, cercana a pleamar (Servicio de Hidrografía Naval), velocidad del viento $33 \mathrm{~km} / \mathrm{h}$ (Servicio Meteorológico Nacional, estación

Punta Indio).

Salix humboldtiana (sauce) es también una especie pionera. Su desarrollo requiere de periodos hidrológicos sin grandes variaciones, que faciliten su asentamiento. Crece a partir de la formación de cordones costeros donde el sustrato húmedo y escasamente consolidado, y la elevada proporción de nutrientes resultan un ambiente propicio (Niiyama, 1990). El proceso de sedimentación a través de mecanismos físicos y químicos, entre ellos disminución de la velocidad de la corriente, la consiguiente pérdida de la capacidad de transporte de sedimentos, y la rugosidad biológica permiten la atenuación del escurrimiento (Depetris et al., 1992). Erythrina crista-galli (ceibo) también coloniza los cordones costeros y luego permanece en zonas más altas, a medida que la marisma evoluciona hacia la madurez (Kandus y Malvarez, 2004).

Los resultados del análisis efectuado por Kokot y Guerrieri (2005) en base a la utilización de cartas topográficas y planos oficiales evidencian alternancias entre erosión y acreción en la zona interna e intermedia del litoral estuarino argentino, siendo la superficie total acrecionada de $38,1 \mathrm{~km}^{2}$ y erosionada de $18,94 \mathrm{~km}^{2}$. Entre las primeras, se destaca la zona de Punta Indio, al sur del área de estudio. En base a un análisis multitemporal de la línea de costa utilizando fotografías aéreas e imágenes satelitales, D’Amico et al. (2016) identificaron un área erosionada de $1,78 \mathrm{~km}^{2}$ entre 1984 y 2000, mientras que Cellone et al. (2016) enuncian un retroceso lineal de $-3,6 \mathrm{~m} / \mathrm{a}$ en la zona urbana y $-0,4 \mathrm{~m} / \mathrm{a}$ en zonas rurales entre 1943 y 2013 . La erosión fue asociada con la modificación de la vegetación de los humedales costeros producto de la actividad turística y de los asentamientos poblacionales, sumado a la variabilidad de los vientos y el incremento del nivel medio del mar en las últimas décadas.

En la costa de la zona externa del estuario, Lamaro et al. (2009) analizaron la formación de marismas y cambios en la línea de costa de la Bahía Samborombón, concluyendo que las primeras han progradado en las últimas cuatro décadas, a pesar del aumento en el nivel medio del mar, en coincidencia con Bértola et al. (1993), Bértola (1994) y Dalmau (1996) que registran una acreción media de 597 m lineales entre 1968 y 2004 en el centro 
de la bahía, y una media de 456 m en Punta Rasa entre 1938 y 2008, siendo los casos de erosión muy puntuales. Sin embargo, Codignotto et al. $(2011,2012)$, registraron un retroceso de la línea de costa de 300 a 50 m lineales en el área central de la bahía, siendo su hipótesis principal el incremento en la frecuencia y altura del oleaje proveniente del $\mathrm{E}$ y ESE en el periodo 1975-2005, asociado a un cambio en el patrón de los vientos.

En contrapartida a la tendencia erosiva descripta, y coincidiendo con el estudio de Kokot y Guerrieri (2005), la costa de Punta Atalaya registra una tendencia acrecional en todo el periodo considerado en el presente trabajo (1929-2016). Mientras que el proceso de acreción se acentúa desde la década de 1970, en Punta del Indio, en cambio, la erosión es el proceso predominante desde la década de 1950. La constante erosión de las playas del balneario El Pericón es una problemática que amenaza la vocación turística de la localidad de Punta del Indio (D’Amico et al., 2016 y Cellone et al., 2016). Mientras tanto, la acreción en la costa de Atalaya ha propiciado la ampliación del espacio turístico-recreativo, tal como ocurre también en Isla Paulino (D’Amico et al., 2018).

\section{Conclusiones}

Los estudios acerca de las dinámicas de los litorales costeros suelen emplear escalas de análisis regionales, donde ciertos procesos, como la erosión y la acreción, se abordan de manera generalizada. Sin embargo, la escala micro espacial revela la particular interacción entre los flujos estuarinos vinculados a las dinámicas hidrológicas, meteorológicas y sedimentarias y las transformaciones derivadas de la valoración social de los mismos a través del tiempo. Esta interacción configura y reconfigura los espacios litorales, aportando especificidad a los mismos.

Metodológicamente, el análisis multitemporal de la línea de costa en base a la utilización de fotografías aéreas e imágenes satelitales de alta resolución presenta la ventaja de obtener datos históricos a escala de detalle. Para lograr una aproximación al análisis, es aconsejable que dicha información se complemente con inspección en campo y bibliografía específica.

Como resultado, se determinó que la costa de Punta Atalaya, en la margen argentina del estuario rioplatense, presenta una tendencia progradante en el último siglo, registrando una acreción de hasta $360 \mathrm{~m}$ lineales. Partiendo de la formación de un cordón costero en la década de 1970 que encerró un pequeño humedal alimentado por canales de marea, la progresiva sedimentación debido al crecimiento de la vegetación y a la interrupción del funcionamiento de los canales por caminos, ha acelerado el proceso de colmatación. En el frente costero, estructuras como las nuevas escolleras del puerto deportivo del balneario de Atalaya y el murallón del balneario de Magdalena actúan interceptando sedimentos transportados por deriva litoral, en el primer caso, y reflejando la energía del oleaje, en el segundo, por lo que el nuevo humedal no presenta una estructura uniforme.

A pesar de la tendencia progradante, procesos de erosión son registrados considerando escalas espaciales y temporales de detalle, debido principalmente a eventos de alta energía como las sudestadas, fuertes vientos del SE que provocan un efecto en el oleaje capaz de remover grandes cantidades de sedimento en poco tiempo. Si bien la 
vegetación costera no garantiza la mitigación total del impacto, actúa disminuyendo la energía de las olas, por lo cual es aconsejable su conservación. Sin embargo, y debido a que la configuración de la costa se encuentra en constante transformación, cada evento puede desencadenar múltiples procesos y tener impactos también diferenciales. En este sentido, las nociones de equilibrio en los balances sedimentarios no resultan suficientes para explicar la dinámica costera.

La nueva superficie acrecionada es plausible de ser valorada con nuevos usos y categorías de protección. En este sentido, la nueva costa entre los balnearios de Atalaya y Magdalena es valorada actualmente para la realización de actividades recreativas, como el turismo, la pesca y la navegación, similar a lo que ocurre en Isla Paulino, otra área de acreción al norte del área de estudio, aunque aún no cuenta con categorías de protección que consideren al humedal como un sistema complejo.

\section{Referencias}

Allen, J. 2000. Morphodynamics of Holocene salt marshes: a review sketch from the Atlantic and Southern North Sea coasts of Europe. Quaternary Science Reviews 19 (12), 1155-1231. https://doi.org/10.1016/S0277-3791(99)00034-7.

Balay, M. 1961. El Río de la Plata entre la Atmósfera y el Mar. Servicio de Hidrografía Naval, Publ. H. 621.

Baldwin, A., Barendregt, A., Whigham, D., Baldwin, A. 2009. Tidal freshwater wetlands, an introduction to the ecosystem. En: A. Barendregt, D. Whigham, A. Baldwin (Eds.), Tidal freshwater wetlands. Backhuys Publisher, Netherlands, pp. 1-10.

Bértola, G., Massone, H., Osterrieth, M. 1993. Estudio geológico integral de Punta Rasa, cabo San Antonio, provincia de Buenos Aires. Serie Situación Ambiental de la Provincia de Buenos Aires (CIC) 25, pp. 1-28.

Bértola, G. 1994. Geomorfología y sedimentología de los ambientes mareales de la Bahía Samborombón, provincia de Buenos Aires. Tesis doctoral, Facultad de Ciencias Naturales y Museo, Universidad Nacional de La Plata (inédito), 153 pp.

Bischoff, S. 2005. Sudestadas. En: V. Barros, A. Menéndez, G. Nagy (Eds.), El cambio climático en el Río de la Plata. CIMA, Buenos Aires, pp. 53-68.

Boak, E.H., Turner, I. 2005. Shoreline definition and detection: A review. Journal of Coastal Research 21 (4), 688-703. https://doi.org/10.2112/03-0071.1.

Borrelli, M. 2009. 137 years of Shoreline Change in Pleasant Bay: 1868-2005. Technical report submitted to the Pleasant Bay Resource Management Alliance. Harwich, Massachusetts, 29 pp.

Boschi, E. 1987. El ecosistema estuarial del Río de la Plata (Argentina y Uruguay). Anales del Instituto de Ciencias del Mar y Limnología de la Universidad Nacional Autónoma de México15, pp. 159-182.

Bouma, T., Olenin, S., Reise, K., Ysebaert, T. 2009. Ecosystem engineering and biodiversity in coastal sediments: posing hypotheses. Helgoland Marine Research 63 (1), 95-106. https:// doi.org/10.1007/s10152-009-0146-y.

Canziani, O., Canziani P., Fernández Cirelli, A., Codignotto, J., Giménez, J., Giraut, M., Volpedo, A. 2013. Análisis de vulnerabilidad al Cambio Climático del Sitio Ramsar Bahía Samborombón y su zona de influencia. En: Fundación Vida Silvestre Argentina. Aportes para abordar la Adaptación al cambio Climático en la bahía Samborombón. Boletín técnico de la Fundación Vida Silvestre Argentina, 256 pp. 
Carol, E., Kruse, E., Tejada, M. 2013. Surface water and groundwater response to the tide in coastal wetlands: Assessment of a marsh in the outer Río de la Plata estuary, Argentina. Journal of Coastal Research, Special Issue International Coastal Symposium, Volume 2, pp. 1098-1103. https://doi.org/10.2112/SI65-186.1.

Carut, C. 2014. La metropolización costera de la Región Metropolitana de Buenos Aires: Un juego dialéctico de los lugares: Entre la inserción y su aislamiento en la nueva metropolización de la década de los 90. Tesis Doctoral. Universidad Nacional de La Plata. Facultad de Humanidades y Ciencias de la Educación, 216 pp.

Cavallotto, J. 1995. Evolución Geomorfológica de la Llanura Costera del Margen Sur del Río de La Plata. Tesis doctoral (inédita), UNLP-FCNyM.

Cavallotto, J. 2002. Evolución holocena de la llanura costera del margen sur del Río de la Plata. Revista de la Asociación Geológica Argentina 57 (4), 376-399.

Cellone, F., Carol, E., Tosi, L. 2016. Coastal erosion and loss of wetlands in the middle Río de la Plata estuary (Argentina). Journal of Applied Geography 76, 37-48. https://doi.org/10.1016/j. apgeog.2016.09.014.

Codignotto J., Kokot, R. 2005. Topografía. En: B. Barros, A. Menéndez, G. Barros (Eds.), El cambio climático en el Río de la Plata. CIMA-CONICET, Buenos Aires, pp. 107-111.

Codignotto, J., Dragani, W., Martin, P., Campos, M., Alonso, G., Simionato, C., Medina, R. 2011. Erosión en la bahía de Samborombón y cambios en la dirección de los vientos, provincia de Buenos Aires, Argentina. Revista del Museo Argentino de Ciencias Naturales 13, 135-138.

Codignotto, J., Dragani, W., Martin, P., Simionato, C., Medina R., Alonso, G. 2012. Wind-wave climate change and increasing erosion in the outer Río de la Plata, Argentina. Continental Shelf Research 38, 110-116. https://doi.org/10.1016/j.csr.2012.03.013.

D’Amico, G., Fucks, E., Salinas Salmuni, G., Carut, C. 2016. Cambios en la línea de costa relacionados a procesos de erosión y depositación en el partido de Punta Indio (Buenos Aires, Argentina) mediante imágenes satelitales de resolución media. XVII Simposio Internacional SELPER, Iguazú.

D’Amico, G., Ghetti, G., Botana M., Carut, C. 2018. Puerto La Plata: El devenir de un territorio en constante resignificación. En: L. López Molina (Ed.), Cádiz: Del floreciente S. XVIII al Port of the Future del S. XXI. Dikinson, Madrid, pp. 99-114.

Dabrio, C. 1982. Sedimentary structures generated on the foreshore by migrating ridge and runnel systems on microtidal and mesotidal coasts of s. Spain. Sedimentary Geology, 32, 141-151. https://doi.org/10.1016/0037-0738(82)90018-5.

Dalmau, M.L. 1996. Transporte de sedimentos en la zona de rompientes Cabo San Antonio, Provincia de Buenos Aires. Seminary Work, ITBA, 40 pp.

Davidson-Amott, R. 2010. Cliffed and rocky coasts. Introduction to Coastal Processes and Geomorphology. Cambridge University Press, Cambridge, 442 pp.

Depetris, C., Orfeo, O., Neiff, J.J. 1992. Atenuación del escurrimiento fluvial por bosques de Tessaria integrifolia. Ambiente subtropical 2, 33-43.

Dragani, W., Martín, P., Alonso, G., Codignotto, J., Prario, B., Bacino, G. 2013. Wind wave climate change: Impacts on the littoral processes at the northern Buenos Aires coast, Argentina. Revista Museo Argentino de Ciencias Naturales 16 (2), 107-113.

Feagin, R.A., Lozanda-Bernard, S.M., Ravens, T.M., Möller, I., Yeager, K.M., Baird, A.H. 2009. Does vegetation prevent wave erosion of salt marsh edges? Proceedings of the National Academy of Sciences 106, 1009-1011. https://doi.org/10.1073/pnas.0901297106.

Fiedler, P., White, P., Leidy, R. 1997. The paradigm shift in ecology and it implications for conservation. En: S. Pickett, R. Ostfeld, M. Shachak, G. Likens (Eds.), The Ecological Basis of Conservation, Heterogeneity, Ecosystems, and Biodiversity. Chapman and Hall, New York, pp. 83-92. https://doi.org/10.1007/978-1-4615-6003-6. 
Figueroa, J. 1898. Estudios sobre puertos de la Provincia de Buenos Aires. Talleres de Publicaciones del Museo, La Plata.

Fletcher, C., Rooney, J., Barbee, M., Lim, S., Richmond, B. 2003. Mapping shoreline change using digital ortho photogrammetry on Maui, Hawaii. Journal of Coastal Research 38, 106-124. https://pubs.er.usgs.gov/publication/70025169.

Ford, M. 2012. Shoreline Changes on an Urban Atoll in the Central Pacific Ocean: Majuro Atoll, Marshall Islands. Journal of Coastal Research 28 (1), 11-22. https://doi.org/10.2112/ JCOASTRES-D-11-00008.1.

Frankl, A., Zwertvaegher, A., Poesen, J., Nyssen, J. 2013. Transferring Google Earth observations to GIS-software: example from gully erosion study. International Journal of Digital Earth 6 (2), 196-201. https://doi.org/10.1080/17538947.2012.744777.

Fucks, E., Schnack, E., Pisano, M., Briones, L., Nuccetelli, G., Charó, M. 2014. Procesos de formación y colmatación de la ensenada de Barragán, partido de Ensenada, provincia de Buenos Aires. XIX Congreso Geológico Argentino, Córdoba.

Hoeke, R., Zarillo, G., Synder, M., 2001. A GIS Based Tool for Extracting Shoreline Positions from Aerial Imagery (BEACHTOOLS) (Coastal Engineering Technical Note IV). US Army Corps of Engineers, Washington, $12 \mathrm{pp}$.

Instituto Nacional de Estadística y Censos de la República Argentina (INDEC). Censo Nacional de Población, Hogares y Viviendas 2010. Disponible en https://www.indec.gov.ar/nivel4_ default.asp?id_tema_1=2\&id_tema_2=41\&id_tema_3 $=135$.

Isacch, J., Escapa, M., Fanjul, E., Iribarne, O. 2010. Valoración ecológica de bienes y servicios ecosistémicos en marismas del Atlántico sudoccidental. En: E. Laterra, G. Jobbágy, J.Paruelo (Eds.), Valoración de servicios ecosistémicos. Conceptos, herramientas y aplicaciones para el ordenamiento territorial. INTA, Buenos Aires, pp. 529-551.

Isla, F. 2006. Erosión y defensa costeras. En: F. Isla, C. Lasta (Eds.), Manual de manejo costero para la Provincia de Buenos Aires. Eudem, Mar del Plata, pp. 125-147.

Kalesnik, F., Aceñolaza, P., Malvárez, A. 2008. Regional distribution of native and exotic species in levees of the lower delta of the Paraná River. Biological Science 30, 391-402.http://doi. org/10.4025/actascibiolsci.v30i4.5869.

Kalesnik, F., Aceñolaza P., Hurtado, M., Martínez, J. 2011. Relationship between vegetation of the levee neo-ecosystems and the environmental heterogeneity in the Paraná delta complex in Argentina. Water and environment Journal 25, 88-98. https://doi.org/10.1111/j.17476593.2009.00196.x.

Kandus, P., Malvarez, A. 2004. Vegetation patterns and change analysis in the lower delta islands of the Parana river (Argentina). Wetlands 24 (3), 620-632.

Kokot, R., Guerrieri, J. 2005. Evolución de la línea de costa Argentina. $2^{a}$ Comunicación de Cambio Climático "vulnerabilidad de la zona costera", Fundación Torcuato Di Tella, pp. 97-144.

Lahitte, H., Hurrel, J., 1997. Plantas de la costa. Literature of Latin America, Buenos Aires, 173 pp.

Lamaro A., Torrusio S., Ulibarrena J, Mugni H., Bonetto C. 2009. Mapping of Coastal Changes Applying Maps, Satellite Images and GIS in Samborombón Bay, Argentina. International Journal of Ecology \& Development (IJED) special issue on Coastal Environment 12, 15-27.

Leonardi, N., Defne, Z., Ganju, N., Fagherazzi, S. 2016. Salt marsh erosion rates and boundary features in a shallow Bay. Journal of Geophysical Research: Earth Surface 12. https://doi. org/10.1002/2016JF003975.

López, R., Marcomini, S. 2004. Análisis de los riesgos ambientales por antropogénesis y su valoración frente a los futuros cambios climáticos en el área metropolitana de la ciudad de Buenos Aires. Revista de la Asociación Geológica Argentina 59 (3), 416-422. 
López, R., Marcomini, S. 2011. Problemática de los ambientes costeros: Sur de Brasil, Uruguay y Argentina. Costa de Buenos Aires, Argentina. Croquis, Buenos Aires, 108 pp.

McLoughlin, S., Wiberg, P., Safak, I., McGlathery, K. 2015. Rates and Forcing of Marsh Edge Erosion in a Shallow Coastal Bay. Estuaries and Coasts 38, 620-638. https://doi.org/10.1007/ s12237-014-9841-2.

Medina, R., Codignotto, J. 2013. Evolución del delta del río Paraná y su posible vinculación con el calentamiento global. Revista del Museo Argentino de Ciencias Naturales 15, 191-200.

Meire, P., Vincx, M. (Eds) 1993. Marine and Estuarine Gradients. Proceedings 21st Symposium ECSA, $496 \mathrm{pp}$.

Melo M., Carol, E., Laurencena, P., Deluchi, M. 2017. Características hidrogeomorfológicas del humedal costero de Atalaya (Argentina). En: N. González, E. Kruse, M. Trovatto, P. Laurencena (Eds.), Agua subterránea, recurso estratégico, Tomo I, pp. 246-250.

Mitsch, W., Gosselink, J. 2000. Wetlands. Third Edition. John Wiley \& Sons, New York, 920 pp. https://doi.org/10.1002/rrr.637.

Municipalidad de Magdalena, Provincia de Buenos Aires. Plan estratégico Magdalena 2016-2014. Disponible en: https://www.magdalena.gob.ar/sites/default/files/plan_estrategico.pdf.

Nagy, G., Martínez, C., Caffera, R., Pedrosa, G., Forbes, E., Perdomo, A., López Laborde, J. 1998. Marco hidrológico y climático del Río de La Plata. En: P.G. Wells, G.R. Daborn (Eds.), El río de La Plata, una revisión ambiental. Un informe del proyecto Ecoplata. Dalhousie University, Halifax, pp. 17-72.

Niiyama, K. 1990. The role of seed dispersal and seedling traits in colonization and coexistence of Salix spp. in a seasonally flooded habitat. Ecological Research 5, 317-332.

Odum, W. 1988. Comparative ecology of tidal freshwater and salt marshes. Annual Review of Ecology and Svstematics 19, 147-176.

Passarelli, L., Rolleri, C., Ciciarelli, M., Dedomenici, A., González, G. 2014. Flora vascular de humedales permanentes y transitorios bonaerenses (Buenos Aires, Argentina). Botanica Complutensis 38, 139-154.

Perillo, G., Syvistki, J., Amos, C., Depetris, P., Milliman, J., Pejrup, M., Saito, Y., Snoussi, M., Wolanski, E., Zajaczkowski, M., Stallard, R., Hutton, E., Kettner, A., Meade, R., Overeem, I., Peckham, S. 2007. Estuaries and the sediments: how they deal with each other. INPRINT 3, pp. 3-5.

Piccolo, M., Perillo, G. 1997. Geomorfología e hidrografía de los estuarios. En: E. Boschi (Ed.), El Mar Argentino y sus recursos pesqueros (Vol. 3). Instituto Nacional de Investigación y Desarrollo Pesquero, Secretaría de Agricultura, Ganadería Pesca y Alimentación, Tomo 1, pp. 119-132.

Pickett, S., McDonnell, M. 1993. Human as Components of Ecosystems: A Synthesis. En: M. McDonnell, S. Pickett (Eds.), Humans as Components of Ecosystems. Springer, New York, pp. 310-316. https://doi.org/10.1007/978-1-4612-0905-8_24.

Poder Ejecutivo de la Provincia de Buenos Aires. Decreto N 7.585. 23 de noviembre de 1984.

Pratolongo, P., Kandus, P., Brinson, M. 2007. Net aboveground primary production and soil properties of floating and attached freshwater tidal marshes in the Río de la Plata estuary, Argentina. Estuaries and coast 30 (4), 618-626.

Re, M., Storto, L., Lecertua, E., Kazimierski, L. 2015. Anticipando la Crecida. Inundaciones en La Ribera de Quilmes Mapas de nivel y duración de inundaciones. Instituto Nacional del Agua, 67 pp.

Sarmiento, F. 2001. Diccionario de ecología: paisajes, conservación y desarrollo sustentable para Latinoamérica. Abya Yala, Ecuador, 226 pp.

Senado y Cámara de Diputados de la Provincia de Buenos Aires. Ley N 12.016. 29 de octubre de 1997. 
Simionato,C., Moreira,D., Re, M., Fossati, M. 2011. Estudio de la dinámica Hidro-sedimentologica del Río de la Plata: observación y modelación numérica de los sedimentos finos. Proyecto FREPLATA, 108 pp.

Stampella, P., Doumecq, M., Vojkovic, M., Laborda, L. 2016. Assessment of environmental change according to "junqueros" and "leñateros" in the southern sector of the Río de la Plata region (Argentina). Bonplandia 25 (1), 17-31.

Temmerman, S., Bouma, T., van de Koppel, J., van der Wal, D., Bries, M., Herman, P. 2007. Vegetation causes channel erosion in a tidal landscape. Geology 35 (7), 631-634. https://doi. org/10.1130/G23502A.1.

Thieler, E., Himmelstoss, E., Zichichi, J., Ergul, A. 2009. Digital Shoreline Analysis System (DSAS) version 4.0 - An ArcGIS extension for calculating shoreline change. U.S. Geological Survey Open-File Report 2008-1278.

Tomazín, N., Cáceres, R. 2014. Estudio del clima de olas en el Río de la Plata mediante el análisis de datos de olígrafo. $2^{\circ}$ Encuentro de investigadores en formación en recursos hídricos, Ezeiza.

Tossini, L. 1959. Sistema hidrográfico y Cuenca del Río de la Plata. Contribución al estudio de su régimen hidrológico. Anales de la Sociedad Científica Argentina, 163, 41-64.

Urien, C. 1966. Distribución de los sedimentos en el Río de la Plata Superior, Tirada Aparte del Boletín del Servicio de Hidrografía Naval, Volumen III (3), pp. 197-203.

Urien, C. 1972. Río de la Plata Estuary environments. Geological Society of America Memoirs 133, 21-234.

van de Koppel, J., Rietkerk, M., Dankers, N., Herman, P. 2005. Scale-dependent feedback and regular spatial patterns in young mussel beds. The American Naturalist 165, 66-77.

Wells, J. 1995. Tide-dominated estuaries and tidal rivers. Developments in Sedimentology 53, 179-205.

Wells, R., Darbon, G. 1998. Río de la Plata; una revisión ambiental: un informe de antecedentes del proyecto EcoPlata. Dalhousie University, Halifax, $256 \mathrm{pp}$.

Yapp, R., Johns, D., Jones, O. 1917. The salt marshes of the Dovey Estuary. Part II. The salt marshes. Journal of Ecology 5, 65-103. 